\title{
COMPOSIÇÃO DO GASTO PÚBLICO E CRESCIMENTO ECONÔMICO: UMA AVALIAÇÃO MACROECONÔMICA DA QUALIDADE DOS GASTOS DOS ESTADOS BRASILEIROS
}

\author{
Fabiana Rocha ${ }^{\S}$ \\ Ana Carolina Giuberti ${ }^{\circ}$
}

\begin{abstract}
RESUMO
O objetivo deste artigo é determinar que componentes do gasto público influenciaram o crescimento econômico dos Estados brasileiros durante o período 1986-2003. Faz-se a decomposição dos gastos segundo sua categoria econômica (gastos correntes, excetuando-se os juros da dívida, e de capital) e também segundo sua categoria funcional (gastos com transporte e comunicação, educação, saúde e defesa). Os gastos de capital aparecem como produtivos, ou seja, estimulam o crescimento econômico, enquanto que os gastos correntes são produtivos até um limite de $61 \%$ da despesa orçamentária. Os gastos com transporte e comunicação, educação e defesa também contribuem para o crescimento dos Estados.
\end{abstract}

Palavras-chave: composição do gasto público, crescimento econômico, Estados.

\begin{abstract}
The purpose of this paper is to determine which components of public expenditure explained the Brazilian states'economic growth during the period 1986-2003. Expenditures are decomposed according to their economic classification (current and capital expenditures), and also according to their functional classification (transportation and communication, education, defense and health). Capital expenditures seem to be productive, that is, they enhance economic growth, while current expenditures are productive only if they represent less than $61 \%$ of total expenditure. Expenditures on transportation and communication, education, and defense also contribute to economic growth.
\end{abstract}

Key words: public expenditure composition, economic growth, Brazilian states.

JEL Classification: E62, H50, O40.

$\S \quad$ Professora do Departamento de Economia da FEA/USP.E-mail: frocha@usp.br.

a Professora do Departamento de Economia da Universidade Federal do Espírito Santo. E-mail: anagiuberti@yahoo.com.br. Endereço para contato: Departamento de Economia - Universidade Federal do Espírito Santo - Av. Fernando Ferrrari, no 514, Campus de Goiabeiras, Vitória, ES. CEP 29075-910.

Recebido em fevereiro de 2007. Aceito para publicação em outubro de 2007. 


\section{INTRODUÇÃo}

Existe uma ampla literatura que discute a relação entre tamanho do governo e crescimento econômico. ${ }^{1}$ Contudo, sabe-se muito menos sobre como a composição do gasto público afeta a taxa de crescimento de um país. Dois fatores justificam a importância de se olhar também para a composição. Primeiro, enquanto o tamanho do governo é uma questão de escolha pública, sua composição é objeto de disputa política. A distinção entre gastos públicos "produtivos" e "improdutivos" e o estabelecimento de como um país pode melhorar seu desempenho econômico, mudando a combinação entre os dois, pode ajudar na acomodação dessa disputa. Segundo, depois de sucessivos ajustes fiscais, enfrenta-se a difícil questão de onde fazer cortes fiscais adicionais. Que componente do gasto público deve ser cortado? A resposta deve, obviamente, depender, entre outras coisas, da contribuição que cada um dos componentes do gasto tem para o crescimento econômico.

$\mathrm{Na}$ literatura existem duas maneiras de avaliar a qualidade do gasto público e seu impacto sobre o crescimento. A primeira é indireta e consiste em avaliar o resultado dos gastos que teriam um efeito positivo sobre o crescimento (por exemplo, gastos com saúde, educação, etc...) e, então, tentar medir o desempenho do setor público relacionando estas medidas de resultado/produto aos insumos utilizados. A segunda é direta e procura medir o impacto do gasto público sobre o crescimento econômico por meio de análise estatística/econométrica ou estudos de caso. Os gastos são, em geral, classificados em "produtivos" e "improdutivos”, de acordo com o seu efeito sobre o nível de atividade, possuindo os primeiros impacto positivo e os últimos impacto negativo sobre o crescimento econômico. ${ }^{2}$

O objetivo deste artigo é avaliar empiricamente o impacto do gasto público sobre o crescimento econômico sustentado, usando a segunda abordagem. A preocupação, contudo, não é com a evidência sobre as conseqüências estimuladoras (ou inibidoras) do gasto público agregado sobre o crescimento, ou seja, com o chamado "efeito tamanho" do gasto sobre o crescimento. A preocupação é com os efeitos da composição do gasto público sobre o crescimento, trabalhando-se ainda no agregado, mas num nível abaixo do efeito tamanho.

Procura-se avaliar mais especificamente que componentes do gasto público contribuem para o crescimento econômico dos Estados brasileiros durante o período 1986-2003. Os gastos são decompostos inicialmente de acordo com suas características econômicas (correntes ou de capital). Em seguida, são decompostos de acordo com sua classificação funcional e quatro categorias principais são avaliadas: defesa, educação, saúde, transporte e comunicação.

No que diz respeito à avaliação do impacto da política fiscal sobre o crescimento econômico dos Estados, o único trabalho parece ser o de Lledó e Ferreira (1997), que, no entanto, procura avaliar as relações de longo prazo entre taxação e crescimento econômico para os Estados no período 1970-1990. A evidência encontrada indica que cargas tributárias mais elevadas, por um lado, desestimulam o crescimento ao diminuírem a taxa de retorno líquida dos investimentos e, por outro, aumentam o crescimento, ao terem como contrapartida investimentos públicos mais elevados. O presente artigo pretende preencher uma lacuna existente na literatura nacional, olhando para o efeito da composição do gasto público em âmbito estadual.

1 Para uma resenha ver Lindauer e Velenchik (1992).

2 Para uma revisão extensiva da literatura relacionando a qualidade das finanças públicas em geral, ou seja, o nível e a composição do gasto público, o seu financiamento e o crescimento econômico, ver Afonso, Ebert, Schuknecht e Thone (2005). 
O artigo está organizado da seguinte maneira: a segunda seção faz uma discussão da literatura sobre efeitos da composição do gasto público sobre o crescimento econômico; a terceira seção apresenta rapidamente o modelo teórico; a quarta seção discute os dados, estabelece a especificação básica do modelo a ser estimado e apresenta os resultados obtidos; a quinta seção realiza alguns testes de robustez da especificação básica; finalmente, a sexta seção apresenta as conclusões e traz, a partir dos resultados obtidos, algumas indicações de política.

\section{REVISÃO DA LITERATURA}

\section{1 A literatura internacional}

No curto prazo, o efeito da política fiscal sobre o crescimento econômico é objeto de debate. Os modelos keynesianos de demanda agregada sugerem relações simples entre o orçamento do governo e a atividade econômica, com um corte no déficit do governo (via aumento de impostos e/ou redução dos gastos), por exemplo, reduzindo consumo e produto. Embora tais modelos influenciem pesadamente o desenho de políticas de estabilização, suas previsões, contudo, nem sempre se mostraram consistentes com a realidade. Em muitos países, cortes grandes nos gastos do governo, feitos como parte de programas de estabilização, levaram a expansões ao invés de contrações fiscais e vice-versa.

Esta evidência deu início ao que ficou conhecido como "visão expectacional da política fiscal", uma vez que partia da percepção de que a análise keynesiana tradicional ignorava o aspecto de sinalização do aumento nos gastos e/ou corte nos impostos. A idéia é que o efeito de um aumento no gasto do governo, por exemplo, depende do aumento resultante nas obrigações futuras de impostos. Mais especificamente, os indivíduos reagem a um sinal fiscal mudando suas distribuições de probabilidade para todos os gastos e impostos futuros. Suponha que aumentos grandes no gasto público sejam tomados como sinal de transição para um regime de gastos mais altos e, portanto, impostos permanentemente mais altos. Se esse é o caso, um aumento grande nos gastos do governo reduz o consumo privado, e o resultado é um efeito contracionista dessa política fiscal. Por outro lado, se aumentos pequenos são vistos como temporários, espera-se que sejam revertidos no futuro. Neste caso, um aumento pequeno nos gastos não afeta o consumo privado (Feldstein, 1982). ${ }^{4}$

Estudos empíricos confirmaram que "contrações fiscais expansionistas" e "expansões fiscais contracionistas" efetivamente acontecem, e tentaram analisar sob que condições uma consolidação fiscal implica um "boom” ou, contrariamente, uma expansão fiscal traz uma recessão. Um dos determinantes apresentados na literatura para a existência de não-linearidades da política fiscal é a composição do gasto público e do ajustamento fiscal (Alesina e Perotti, 1995; 1997) e Alesina e Ardagna (1998). ${ }^{5}$ São identificados dois tipos de consolidação fiscal: a) Tipo 1: ajustamento que se

3 São exemplos de experiências de "contrações fiscais expansionistas” a Dinamarca em 1983-1986, a Irlanda em 1986-1989, a Grécia em 1990-1994 e a Suécia em 1986-1987. Por outro lado, existem também exemplos de "expansões fiscais contracionistas" como a Suécia em 1990-1993, a Finlândia em 1977-1980 e 1990-1992, a Suécia em 1977-1979, o Japão em 1990-1994 e a Austrália em 1990-1994.

4 Outras referências na literatura sobre efeitos anti-keynesianos da política fiscal são: Bertola e Drazen (1993), Sutherland (1997), Perotti (1999).

5 Outras razões apontadas na literatura para que uma consolidação fiscal tenha uma maior probabilidade de ser expansionista são: uma dívida pública alta ou que cresce rapidamente (Perotti, 1999) e o tamanho e a persistência do impulso fiscal (Giavazzi e Pagano, 1990; 1995). 
baseia principalmente em cortes de gastos, em particular, cortes nas transferências, na seguridade social, nos salários do governo e no emprego; b) Tipo 2: ajustamento que se baseia principalmente no aumento de impostos. Do lado dos gastos, quase todos os cortes são no investimento público.

Alesina e Perotti $(1995 ;$ 1997) obtêm evidências de que consolidações fiscais têm maior probabilidade de serem bem sucedidas quando a melhora orçamentária é obtida cortando-se os salários públicos e os benefícios previdenciários (ajustamento Tipo 1). ${ }^{6}$ Este resultado é consistente com a visão de que os efeitos da política fiscal dependem de como eles afetam as expectativas. Cortando estes itens "intocáveis" do orçamento, o governo sinaliza que uma mudança de regime ocorreu, o que estimula, então, o produto por meio de uma onda de otimismo. Além do mais, cortes nos investimentos públicos são claramente temporários e devem ser retomados em algum momento no futuro. Para os países industrializados, são observadas as seguintes conseqüências macroeconômicas dos ajustamentos fiscais bem sucedidos: um crescimento acima da média dos países; uma taxa de crescimento do investimento privado maior, e um desemprego em relação à média mais ou menos constante.

No longo prazo, apesar da ampla pesquisa sobre a relação entre tamanho do governo e crescimento econômico, há uma literatura relativamente escassa discutindo a relação entre composição do gasto público e crescimento econômico. Na realidade, nem a teoria econômica nem a evidência empírica fornecem respostas claras para a questão de como a composição do gasto público afeta o crescimento econômico de longo prazo.

A teoria desenvolve uma racionalidade para a provisão pelo governo de bens e serviços públicos. Bens e serviços devem ser ofertados pelo setor público quando os mercados privados falham em fornecer esses bens, quando é necessário internalizar externalidades e quando existem economias de escala significativas. Além disso, quando há falha num mercado, a intervenção do governo em outro mercado relacionado também pode ocorrer. O problema é que essas justificativas teóricas para a existência do governo não são capazes de serem traduzidas em regras operacionais, indicando que componentes do gasto público devem ser cortados.

No que diz respeito à literatura empírica, alguns pesquisadores tentaram ligar componentes particulares do gasto do governo à produtividade do setor privado e crescimento econômico, mas a maioria desses esforços não tem uma estrutura teórica rigorosa. Exceções são Aschauer (1989), Morrison e Schwartz (1991) e Holtz-Eakin (1991) que se basearam em modelos teóricos, porém tendo como objetivo a análise da produtividade dos gastos públicos nos Estados Unidos. Devarajan et al. (1996) consistem em uma exceção adicional no sentido de que, além de desenvolverem uma estrutura teórica ligando composição do gasto público com crescimento econômico, têm como foco o caso dos países em desenvolvimento.

Aschauer e Greenwood (1985), Barro (1990) e outros enfatizaram a distinção entre bens e serviços públicos que entram na função utilidade e aqueles que complementam a produção do setor privado. Os primeiros parecem ter efeitos negativos sobre o crescimento. Isto porque, ainda que forneçam utilidade para as famílias, os impostos mais altos, necessários para financiá-los, reduzem o retorno dos investimentos privados, o incentivo a investir e, conseqüentemente, o crescimento. Isto é confirmado por Grier e Tullock (1989) Usando dados em painel (115 países, incluindo 24 países da OCDE, no período pós-Segunda Guerra Mundial) eles acham uma relação negativa e estatisticamente significante entre a taxa de crescimento real do produto e a participação do consumo do

6 São consideradas bem sucedidas aquelas contrações fiscais que, em três anos, reduzem a razão dívida/PIB em pelo menos $5 \%$. Outro trabalho no mesmo estilo e mesmas evidências é o de McDermott e Wescott (1996). 
governo no PIB. Ao contrário, gastos com investimento (tais como a provisão de infra-estrutura) fornecem um ambiente que estimula o crescimento.

Aschauer (1989) encontra evidência de um impacto positivo do investimento público (em particular estradas, ruas, sistemas de água, etc.) sobre o crescimento econômico e a produtividade do setor privado nos Estados Unidos no período 1949-1985.

Usando um conjunto de regressões em cross-section, Easterly e Rebelo (1993) encontram que o investimento público em transporte e comunicação, em países em desenvolvimento, leva a um maior crescimento econômico. Para outras categorias de gasto público, as evidências não são de fato conclusivas se eles constituem gastos "produtivos".

Enquanto Kormendi e Meguire (1985), Grier e Tullock (1989) e Summers e Heston (1988) classificam defesa e educação como gastos do governo e, portanto, improdutivos; Barro (1991) modela os mesmos como produtivos. Isto porque gasto com educação pública representa, na verdade, investimento em capital humanO. Da mesma forma, gastos com segurança ajudam a proteger os direitos de propriedade, o que aumenta o investimento e o crescimento. Usando dados de 98 países, Barro (1991) conclui que um aumento dos recursos destinados a gasto não produtivo está associado a uma taxa de crescimento per capita menor.

Devarajan et al. (1996) procuram determinar que componentes dos gastos públicos podem ser considerados produtivos em países em desenvolvimento. Eles evitam classificar a priori os gastos públicos em produtivos ou improdutivos. Ao invés disso, eles deixam os dados dizerem que componentes atendem à definição de gasto produtivo. Os resultados empíricos, para um conjunto de 43 países em desenvolvimento ao longo de 20 anos, indicam que os gastos que normalmente são considerados produtivos podem se tornar improdutivos quando são feitos em excesso. Este seria o caso dos gastos com capital, transporte e comunicação, saúde e educação. Somente os gastos correntes, como categoria ampla, estão associados com maior crescimento econômico. Isto resulta do fato de os países em desenvolvimento terem concentrado seus gastos em capital ao invés de custeio. Desta forma, a recomendação tradicional de aumentar a parcela do investimento público no orçamento para promover o crescimento - que valeria para os países desenvolvidos uma vez que esses investiram relativamente mais em custeio - não é correta para os países em desenvolvimento.

Kneller et al. (1999) agregam as classificações fiscais do FMI em 7 categorias e testam a sensibilidade dos resultados a esta classificação dos dados. Do lado dos gastos, esses são classificados em produtivos (gastos com serviços públicos gerais, defesa, educação, saúde, transporte e comunicação), improdutivos (seguridade social, recreação, serviços econômicos) e outros gastos (aqueles de classificação ambígua). Para um painel de países da OCDE para o período 1970-1995, eles acham evidência de que gastos produtivos estimulam o crescimento, enquanto gastos não produtivos não estimulam crescimento.

\subsection{Evidências para a economia brasileira}

Alguns estudos relacionando política fiscal e crescimento econômico foram desenvolvidos para a economia brasileira. Entretanto, o foco desses estudos se concentrou ou no impacto dos gastos agregados sobre o crescimento ou no impacto somente dos investimentos em infra-estrutura (e não nos efeitos diferenciados da composição dos gastos) sobre o crescimento. 
Dois trabalhos mostram que o impacto dos investimentos em infra-estrutura sobre o crescimento da economia brasileira é positivo no longo prazo. Ferreira (1996) encontra esse resultado para o período de 1970-1993, considerando como capital federal de infra-estrutura o capital investido em telecomunicações, energia elétrica, portos, setor marítimo e ferrovias. Já Ferreira e Malliagros (1998), observam esse mesmo impacto positivo, para o período 1950-1995, considerando o setor rodoviário ${ }^{7}$ nos gastos em infra-estrutura. Os autores concluem que o setor de energia elétrica apresentou as maiores elasticidades, sendo seguido pelos setores de transporte e telecomunicações. No que se refere ao setor de transportes, os maiores efeitos sobre o crescimento do produto estavam no subsetor ferroviário, depois no portuário e, finalmente, no rodoviário.

Em relação ao impacto dos gastos públicos agregados sobre o crescimento, a avaliação empírica de Cândido Jr. (2001), para o período de 1947 a 1995, apresenta o seguinte resultado: as estimativas da elasticidade gasto-produto, quando se utiliza o conceito mais restrito de gasto público (consumo mais transferências), aparecem sempre como negativas. No entanto, quando o gasto público passa a incluir também os investimentos das administrações públicas, o impacto passa a ser positivo.

Herrera e Blanco (2004) estimam os impactos de curto e longo prazo da política fiscal sobre o produto. Os resultados mostram que, no longo prazo, a elasticidade-renda do estoque de capital público é maior do que a do setor privado. No que tange ao aspecto tributário da política fiscal, a taxação tem um impacto negativo expressivo sobre o produto. No que diz respeito ao gasto público, as despesas com consumo e previdência social não têm efeito sobre o PIB, enquanto os subsídios apresentam um efeito negativo sobre o mesmo. No curto prazo, os efeitos do capital privado e público sobre o produto se invertem: o capital privado tem um impacto maior do que o capital público. Já os gastos do governo não afetam o nível de produto da economia e os impostos apresentam um efeito negativo sobre o PIB.

Mazoni (2005) também analisa os impactos da política fiscal sobre o produto da economia. ${ }^{8}$ Para tanto, separa os gastos públicos em consumo e investimento, e considera ainda os investimentos privados, pois observa que os impactos dos gastos públicos podem ocorrer de duas formas: diretamente sobre o produto da economia e indiretamente por meio do impacto nos investimentos privados. Os resultados indicam que, durante o período de 1970-2003, existe uma relação de longo prazo negativa entre os gastos em consumo do governo e o produto. Já a relação entre o investimento público e o produto é positiva. Em relação ao investimento privado, seu efeito sobre o PIB também é positivo e cerca de 2,6 vezes maior que o apresentado pelos investimentos públicos. Com o objetivo de determinar se os efeitos de crowding-in (complementaridade) ou crowding-out (substituição) estão presentes na economia brasileira, a autora analisa a relação entre o investimento privado e o investimento público e entre o investimento privado e os gastos de custeio. A conclusão é de que não existe relação de longo prazo entre o investimento público e privado. ${ }^{9}$

7 O argumento é que os resultados para as magnitudes da elasticidade-renda podem ser substancialmente modificados pela inclusão desse setor, uma vez que ele teve uma participação significativa nos investimentos totais ao longo da evolução da economia brasileira.

8 Os trabalhos para a economia brasileira usam técnicas de séries temporais. Fereira (1996), Ferreira e Malliagros (1998) e Mazoni (2005) utilizam análise de cointegração. Cândido Jr. (2001) e Herrera e Blanco (2004) usam um modelo ARDL (autoregressive distributed lag model). Assis e Dias (2004) usam uma abordagem de vetores auto-regressivos, mas apresentam uma preocupação diferente (agregada), qual seja, avaliar o impacto dos gastos e impostos sobre o crescimento econômico. Contudo, o span curto dos dados para os Estados levou imediatamente à necessidade de se trabalhar com as informações em painel neste artigo.

9 Os trabalhos que avaliaram a relação entre investimentos públicos e investimentos privados no Brasil apontam conclusões diversas. Ronci (1991) não encontra relação entre os investimentos público e privado. Sant'ana, Rocha e Teixeira (1994), por sua vez, encontram evidências de que há complementariedade entre os dois tipos de investimento, enquanto Rocha e Teixeira (1996) encontram evidências de substituição entre eles. Souza Jr. e Jayme Jr. (2004) observam que não existe uma relação de longo prazo entre os dois tipos de investimento. 


\section{O MODELO TEÓRICO}

A evidência sobre os efeitos da composição (qualidade) dos gastos sobre o crescimento muitas vezes leva a resultados aparentemente tautológicos: "Specifically we find that (1) distortionary taxation reduces growth, whilst non-distortionary taxation does not; (2) productive government expenditure enhances growth, whilst non-productive expenditure dos not”. (Kneller et al., 1998).

A fim de evitar conclusões deste tipo, segue-se o modelo de Devarajan et al. (1996), que tem como grande mérito não definir a priori que componente do gasto é produtivo ou improdutivo.

Eles assumem uma função de produção com três argumentos: o estoque privado de capital, $k$, e dois tipos de gasto público, $g_{1}$ e $g_{2}$. Se a função de produção é do tipo elasticidade de substituição constante (CES), então:

$$
y=f\left(k, g_{1}, g_{2}\right)=\left[\alpha k^{-\zeta}+\beta g_{1}^{-\zeta}+\gamma g_{2}^{-\zeta}\right]^{-1 / \zeta}
$$

onde $y=f\left(k, g_{1}, g_{2}\right)=\left[\alpha k^{-\zeta}+\beta g_{1}^{-\zeta}+\gamma g_{2}^{-\zeta}\right]^{-1 / \zeta}$.

O governo financia os seus gastos usando uma alíquota de impostos fixa sobre a renda, $\tau$ :

$$
\tau y=g_{1}+g_{2}
$$

A parcela do gasto total do governo que é alocada para $g_{1}, \phi(0 \leq \phi \leq 1)$ é dada por : $g_{1}=\phi y$, o que por sua vez implica que $g_{2}=(1-\phi) \tau y$.

O agente representativo escolhe o consumo $(c)$ e o capital $(k)$ de forma a maximizar o seu bem-estar, tomando as decisões do governo com relação a $\tau$ e $\phi$ como dadas:

$$
U=\int_{0}^{\infty} u(c) e^{-\rho t} d t
$$

sujeito a $\dot{k}=(1-\tau) y-c$, onde $\rho$ é a taxa de preferência temporal.

Assumindo-se que a função de utilidade tem a forma isoelástica, a fim de obter soluções analíticas, deriva-se a relação entre a taxa de crescimento de steady-state e a parcela do gasto do governo destinada a $g_{1}$. Define-se, então, como gasto produtivo aquele que leva a um aumento na taxa de crescimento de steady-state da economia. Esta definição implica que, para uma mudança na composição do gasto aumentar a taxa de crescimento, $\frac{\phi}{1-\phi}<\left(\frac{\beta}{\gamma}\right)^{\theta}$, em que $\theta=1 /(1+\zeta)$ é a elasticidade
de substituição.

Desta forma, o impacto da mudança na composição sobre o crescimento depende não somente da produtividade dos dois componentes do gasto $(\beta$ e $\gamma$ ), mas também das suas parcelas iniciais. Uma mudança na composição em direção a um gasto teoricamente mais produtivo, por exemplo, $\beta>\gamma$, pode não levar a um aumento da taxa de crescimento se a sua parcela no total $(\phi)$ inicialmente já era "muito alta".

De acordo com o modelo, tem-se ainda que o aumento da taxa de crescimento resultante da mudança na composição do gasto pode ocorrer sem qualquer mudança no gasto total. Uma vez que um aumento no gasto total deve ser financiado por impostos de igual montante, só haverá aumento 
na taxa de crescimento se a produtividade deste gasto $(\beta+\gamma)$ for maior do que a receita necessária para o seu financiamento. ${ }^{10}$

\section{ANÁLISE EMPÍRICA}

\subsection{O modelo empírico básico}

Para examinar a ligação entre componentes do gasto do governo e crescimento econômico, utiliza-se um painel composto pelos Estados brasileiros durante o período 1986-2003. ${ }^{11}$

Como o objetivo é avaliar como cada componente do gasto público está associado com a taxa de crescimento, as parcelas de cada um dos componentes do gasto no total do gasto do governo aparecem como as variáveis explicativas. Para controlar para efeitos de nível, inclui-se também a parcela do gasto do governo no PIB. Isto permite que seja controlado o efeito do financiamento dos gastos sobre o crescimento, que é uma função do nível do gasto.

Deve-se levar em conta que existem, ainda, características específicas a cada Estado, que poderiam influenciar a taxa de crescimento per capita. Mesmo que essas características sejam difíceis de medir (por exemplo, fatores culturais), fazer uma regressão com dados agrupados poderia levar a um viés nas estimativas dos coeficientes. Aplica-se, então, o método de efeitos fixos, que leva em conta características específicas dos Estados. São incluídas também variáveis dummies de ano para controlar fatores comuns afetando a taxa de crescimento dos diferentes Estados. Utiliza-se, portanto, a abordagem de efeitos fixos estendida para incluir também um efeito específico de tempo (LSDV model - least squares dummy variable model with a time specific effect).

A equação estimada tem a seguinte forma:

$$
Y_{i t}=\alpha_{i}+\gamma_{t}+\beta^{\prime} X_{i t}+\varepsilon_{i t}
$$

onde:

$Y_{i t}$ é a taxa média de crescimento per capita anual para o período de cinco anos anos adiante. ${ }^{12}$

O resultado dessa especificação da variável dependente é que o modelo estimado abrange o período de 1986 a 1998, pois em 1998, $Y_{i t}$ é a média de crescimento anual para o período de 1999 a 2003, último ano da amostra. Os dados do PIB per capita estadual são do IBGE e foram obtidos por meio do banco de dados disponibilizados pelo IPEA. ${ }^{13}$

$a_{i}$ corresponde aos efeitos específicos de cada Estado.

$g_{t}$ representa as variáveis constantes entre os Estados, mas que variam no tempo. No modelo estimado, corresponde às dummies de an.

$X_{i t}$ consiste de todas as variáveis independentes:

1) $(G T / P I B)_{t}^{i}$ é a parcela do gasto total do governo no PIB para o Estado $i$ no período $t$.

2) $(G / G T)_{t}^{i}$ é um vetor de razões do gasto público para o Estado $i$ no período $t$, ou seja, a participação de cada tipo de gasto no gasto total. Tanto os dados relativos aos gastos dos governos

10 Para a dedução matemática deste resultado, assim como para maiores detalhes do modelo, ver o artigo original.

11 Para o Estado de Tocantins, criado em 1989, a amostra compreende os anos de 1990 a 2003.

12 Segue-se, aqui, o padrão da maior parte da literatura empírica de crescimento econômico que considera cinco anos um período de tempo adequado para captar crescimento de longo prazo.

13 www.ipeadata.gov.br. 
estaduais quanto a classificação dos mesmos foram obtidos por meio da Execução Orçamentária dos Estados, disponibilizada pelo Tesouro Nacional. ${ }^{14}$ A classificação econômica do gasto público é baseada no tipo ou característica econômica do gasto e formada por: i) gastos correntes, que inclui salários, outros bens e serviços, etc.; ii) gastos de capital, que são os gastos com compras ou produção de bens duráveis. Embora a categoria gastos correntes inclua também o pagamento de juros, estes foram desconsiderados por não estarem sob controle do Estado, representando em parte herança de governos anteriores. Além disso, este vetor inclui a classificação do gasto por função do governo. ${ }^{15}$ Especificamente, foram consideradas as frações referentes às despesas com saúde, educação, defesa (que engloba os gastos com segurança pública) e transporte e comunicação (como medida para infra-estrutura).

A defasagem para frente da variável dependente é escolhida por duas razões. Primeiro, porque deve demorar algum tempo para que o gasto público afete o crescimento. Segundo, porque existe um problema de endogeneidade e causalidade reversa entre gasto público e crescimento econômico, que é minimizado uma vez que aqui o gasto em $\mathrm{t}$ afeta o crescimento entre $t+1$ e $t+5$.

\subsection{Os dados}

Para o período 1986-2003, a análise descritiva das variáveis incluídas no modelo acima mostra que a maioria dos Estados brasileiros apresentou um crescimento do PIB per capita muito baixo e, em vários casos, negativo. As exceções foram os Estados de Tocantins, ${ }^{16}$ Mato Grosso, Distrito Federal, Goiás e Paraíba, que cresceram, respectivamente, 3,4\%, 3,3\% , 2,7\%, 2,6\% e 2,4\% ao ano (Tabela 1).

Em relação ao gasto dos governos estaduais, este representou, em média, $21 \%$ do PIB no período analisado, e variou entre 10,7\% e 60,9\% nos Estados do Paraná e Roraima, respectivamente (Tabela 1).

Quando a despesa pública é analisada de acordo com a sua classificação econômica, observase que grande parte desta se concentrou nos gastos correntes primários, que exclui o pagamento de juros da dívida, restando uma pequena parcela destinada ao gasto com capital. A despesa corrente primária média situou-se em torno de $73 \%$ da despesa orçamentária no período, sendo o menor porcentual 55,9\%, em Tocantins, e o maior, 87,1\%, no Distrito Federal. Já a despesa com capital média representou $22 \%$ da despesa orçamentária dos governos estaduais, variando de $11,5 \%$ no Distrito Federal a $42,5 \%$ em Tocantins.

14 www.tesouro.fazenda.gov.br.

15 A classificação do gasto do governo por função apresenta limitações no que tange à correta identificação do gasto público por área de atuação. Por exemplo, no âmbito federal, os gastos com a merenda escolar são alocados no item educação, pois os recursos são distribuídos a partir do Ministério da Educação. O ideal, portanto, seria reclassificar os gastos dentro de cada função, a partir da ação a qual eles correspondem. Infelizmente, esta reclassificação para os gastos estaduais não é possível, pois a execução orçamentária dos Estados não traz informações sobre o gasto por ação do governo.

16 Para o Estado de Tocantins, os valores médios apresentados ao longo deste trabalho referem-se à média do período 1990-2003. 
Tabela 1 - Crescimento e gasto do governo - valores médios referentes ao período 1986-2003

\begin{tabular}{lcccc}
\hline UF & $\begin{array}{c}\text { Crescimento Per Capita } \\
\text { Médio (\% a.a.) }\end{array}$ & Gasto Total/PIB (\%) & $\begin{array}{c}\text { Gasto Corrente Primário/ } \\
\text { Gasto Total (\%) }\end{array}$ & $\begin{array}{c}\text { Gasto com Capital/ } \\
\text { Gasto Total (\%) }\end{array}$ \\
\hline AC & 0,7 & 42,6 & 78,4 & 19,5 \\
AL & $-0,8$ & 18,5 & 81,4 & 11,9 \\
AM & $-0,03$ & 13,0 & 70,0 & 26,4 \\
AP & 0,04 & 39,3 & 75,1 & 24,2 \\
BA & 0,1 & 15,1 & 69,2 & 26,0 \\
CE & 0,8 & 18,6 & 66,5 & 26,6 \\
DF & 2,7 & 14,1 & 87,1 & 11,5 \\
ES & 0,6 & 16,1 & 72,6 & 24,8 \\
GO & 17,8 & 73,1 & 22,2 \\
MA & 2,6 & 22,6 & 63,8 & 30,4 \\
MG & 1,7 & 13,7 & 69,5 & 24,9 \\
MS & 0,6 & 17,9 & 69,4 & 20,9 \\
MT & 1,7 & 22,3 & 71,3 & 21,6 \\
PA & 3,3 & 12,5 & 75,6 & 20,4 \\
PB & 0,7 & 20,2 & 73,0 & 17,6 \\
PE & 2,4 & 14,4 & 78,9 & 16,0 \\
PI & 1,2 & 26,3 & 79,2 & 24,1 \\
PR & 1,9 & 10,7 & 71,1 & 17,7 \\
RJ & 1,4 & 11,2 & 75,3 & 17,9 \\
RN & 0,8 & 13,8 & 79,4 & 17,8 \\
RO & 1,1 & 24,1 & 80,0 & 32,1 \\
RR & $-0,5$ & 60,9 & 67,3 & 21,2 \\
RS & $-0,5$ & 12,4 & 73,3 & 20,4 \\
SC & 1,2 & 11,8 & 74,7 & 42,5 \\
SE & 1,4 & 20,9 & 71,3 & \\
SP & $-1,0$ & 12,5 & 53,6 & \\
TO & $-0,4$ & 53,5 & 55,9 & \\
\hline & 3,4 & & & \\
\hline
\end{tabular}

A Tabela 2, a seguir, traz a média do gasto público, de acordo com sua classificação funcional, para as quatro categorias principais avaliadas. Como esperado, a categoria que recebeu a maior parcela dos recursos é a educação. No período 1986-2003, em média 17\% da despesa orçamentária dos Estados foi direcionada para a educação, sendo o menor porcentual, 13,7\%, no Espírito Santo e o maior, 21,6\%, no Paraná. É importante ressaltar que a Constituição Federal de 1988, em seu art. 212, caput, estabelece que os Estados devem aplicar no mínimo 25\% da sua receita de impostos na manutenção e desenvolvimento do ensino público. Essa obrigatoriedade contribui para a predominância da educação sobre as demais categorias de despesa analisadas.

Os gastos com transporte e comunicação representaram em média 7,2\% do gasto total dos Estados, variando de 3,1\% no Rio Grande do Norte a 24,5\% em Tocantins. Já a parcela média da despesa com saúde situou-se em torno de 9,5\%, com valores entre 3,5\% no Rio Grande do Sul e $18 \%$ no Distrito Federal. Por último, observa-se que o gasto com defesa, que inclui o gasto com segurança pública, representou, em média, apenas 6,7\% do gasto total no período 1986-2003 e oscilou entre 2,7\% no Amapá e 12,3\% no Distrito Federal. 
Tabela 2 - Gasto do governo - valores médios referentes ao período 1986-2002

\begin{tabular}{lcccc}
\hline UF & $\begin{array}{c}\text { Gasto Transporte Comunicação/ } \\
\text { Gasto Total (\%) }\end{array}$ & $\begin{array}{c}\text { Gasto Defesa/ Gasto } \\
\text { Total (\%) }\end{array}$ & $\begin{array}{c}\text { Gasto Educação/ Gasto } \\
\text { Total (\%) }\end{array}$ & $\begin{array}{c}\text { Gasto Saúde/ Gasto } \\
\text { Total (\%) }\end{array}$ \\
\hline AC & 9,2 & 6,0 & 20,5 & 14,3 \\
AL & 4,5 & 9,5 & 17,4 & 10,2 \\
AM & 7,5 & 5,3 & 16,3 & 14,1 \\
AP & 5,7 & 2,7 & 17,4 & 11,3 \\
BA & 5,2 & 6,7 & 17,0 & 12,5 \\
CE & 5,5 & 4,4 & 16,3 & 8,4 \\
DF & 6,0 & 12,3 & 20,7 & 18,0 \\
ES & 5,9 & 7,4 & 13,4 & 10,9 \\
GO & 6,6 & 15,5 & 6,2 \\
MA & 12,1 & 4,6 & 19,5 & 7,0 \\
MG & 4,5 & 7,7 & 18,2 & 7,3 \\
MS & 7,5 & 7,3 & 17,2 & 5,1 \\
MT & 11,1 & 5,8 & 15,1 & 5,7 \\
PA & 10,1 & 7,3 & 20,7 & 11,5 \\
PB & 5,4 & 5,0 & 19,9 & 7,1 \\
PE & 3,5 & 9,2 & 13,8 & 8,8 \\
PI & 4,0 & 8,2 & 21,6 & 10,7 \\
PR & 4,3 & 6,5 & 21,3 & 5,4 \\
RJ & 8,1 & 9,4 & 16,6 & 7,9 \\
RN & 6,3 & 5,1 & 20,2 & 13,4 \\
RO & 3,1 & 10,6 & 19,4 & 9,3 \\
RR & 5,0 & 2,8 & 16,5 & 10,7 \\
RS & 12,6 & 6,9 & 15,1 & 3,5 \\
SC & 5,2 & 7,4 & 16,3 & 6,7 \\
SE & 7,2 & 5,5 & 17,1 & 17,3 \\
SP & 5,8 & 17,8 & \\
TO & 9,0 & 4,9 & & \\
\hline & 24,5 & & 9,7 & \\
\hline
\end{tabular}

\subsection{Resultados do Modelo Básico}

A Tabela 3 contém os resultados do modelo apresentado na Seção 4.1. 
Tabela 3 - Composição do gasto do governo e crescimento econômico - Modelo LSDV (erro padrão)

\begin{tabular}{|c|c|c|c|}
\hline Variáveis Explicativas & (a) & (b) & (c) \\
\hline DespesaTotal/PIB & $\begin{array}{c}0,024 \\
(0,028)\end{array}$ & $\begin{array}{c}0,024 \\
(0,028)\end{array}$ & $\begin{array}{c}0,075 \\
(0,026)^{*}\end{array}$ \\
\hline $\begin{array}{l}\text { Desp. Corrente Primária/ } \\
\text { Despesa Total }\end{array}$ & $\begin{array}{l}-0,010 \\
(0,019)\end{array}$ & & \\
\hline Desp. Capital/Despesa Total & & $\begin{array}{c}0,011 \\
(0,017)\end{array}$ & \\
\hline Desp. Defesa/Despesa Total & & & $\begin{array}{c}0,265 \\
(0,088)^{*}\end{array}$ \\
\hline Desp. Educação/Despesa Total & & & $\begin{array}{c}0,115 \\
(0,030)^{*}\end{array}$ \\
\hline Desp. Saúde/Despesa Total & & & $\begin{array}{c}0,009 \\
(0,039)\end{array}$ \\
\hline Desp. Transporte e Comunicação/Despesa Total & & & $\begin{array}{c}0,124 \\
(0,029)^{*}\end{array}$ \\
\hline 1987 & $\begin{array}{l}-0,013 \\
(0,006)^{* *}\end{array}$ & $\begin{array}{l}-0,013 \\
(0,006)^{* *}\end{array}$ & $\begin{array}{l}-0,010 \\
(0,006)\end{array}$ \\
\hline 1988 & $\begin{array}{l}-0,013 \\
(0,006)^{* *}\end{array}$ & $\begin{array}{l}-0,012 \\
(0,006)^{* *}\end{array}$ & $\begin{array}{l}-0,006 \\
(0,006)\end{array}$ \\
\hline 1989 & $\begin{array}{c}0,021 \\
(0,006)^{*}\end{array}$ & $\begin{array}{c}0,021 \\
(0,006)^{*}\end{array}$ & $\begin{array}{c}0,030 \\
(0,006)^{*}\end{array}$ \\
\hline 1990 & $\begin{array}{l}0,020 \\
(0,006)^{*}\end{array}$ & $\begin{array}{l}0,020 \\
(0,006)^{*}\end{array}$ & $\begin{array}{c}0,022 \\
(0,006)^{*}\end{array}$ \\
\hline 1991 & $\begin{array}{c}0,036 \\
(0,006)^{*}\end{array}$ & $\begin{array}{c}0,036 \\
(0,006)^{*}\end{array}$ & $\begin{array}{c}0,042 \\
(0,006)^{*}\end{array}$ \\
\hline 1992 & $\begin{array}{c}0,029 \\
(0,006)^{*}\end{array}$ & $\begin{array}{c}0,029 \\
(0,006)^{*}\end{array}$ & $\begin{array}{c}0,034 \\
(0,006)^{*}\end{array}$ \\
\hline 1993 & $\begin{array}{c}0,017 \\
(0,006)^{*}\end{array}$ & $\begin{array}{c}0,017 \\
(0,006)^{*}\end{array}$ & $\begin{array}{c}0,021 \\
(0,006)^{*}\end{array}$ \\
\hline 1994 & $\begin{array}{c}0,011 \\
(0,006)\end{array}$ & $\begin{array}{c}0,011 \\
(0,006)\end{array}$ & $\begin{array}{l}0,013 \\
(0,006)^{\star *}\end{array}$ \\
\hline 1995 & $\begin{array}{l}0,017 \\
(0,007)^{* *}\end{array}$ & $\begin{array}{c}0,017 \\
(0,007)^{\star *}\end{array}$ & $\begin{array}{c}0,021 \\
(0,006)^{*}\end{array}$ \\
\hline 1996 & $\begin{array}{l}0,018 \\
(0,007)^{*}\end{array}$ & $\begin{array}{c}0,018 \\
(0,007)^{*}\end{array}$ & $\begin{array}{c}0,024 \\
(0,006)^{*}\end{array}$ \\
\hline 1997 & $\begin{array}{c}0,023 \\
(0,006)^{*}\end{array}$ & $\begin{array}{c}0,023 \\
(0,006)^{*}\end{array}$ & $\begin{array}{c}0,030 \\
(0,006)^{*}\end{array}$ \\
\hline 1998 & $\begin{array}{c}0,025 \\
(0,006)^{*}\end{array}$ & $\begin{array}{c}0,025 \\
(0,006)^{*}\end{array}$ & $\begin{array}{c}0,030 \\
(0,006)^{*}\end{array}$ \\
\hline Constante & $\begin{array}{c}0,994 \\
(0,016)^{*}\end{array}$ & $\begin{array}{c}0,984 \\
(0,007)^{*}\end{array}$ & $\begin{array}{c}0,924 \\
(0,012)^{*}\end{array}$ \\
\hline N..$^{\circ}$ de Obs. & 347 & 347 & 347 \\
\hline
\end{tabular}

Nota: ${ }^{*} \mathrm{e}^{* *}$ significam que as variáveis são estatisticamente significantes aos níveis de $1 \%$ e $5 \%$, respectivamente.

A coluna (a) inclui no vetor de razões do gasto público, a parcela do gasto corrente (exclusive pagamento de juros) no gasto total. 
Observa-se uma relação negativa, porém não estatisticamente significante, entre a taxa de crescimento real per capita e a razão gasto corrente/gasto total, o que indica que este tipo de gasto não possui efeito sobre o crescimento econômico dos Estados. Este resultado, contudo, não é surpreendente, uma vez que a literatura brasileira aponta evidências sistemáticas de que os gastos correntes ou não têm relação com a taxa de crescimento, ou afetam negativamente a taxa de crescimento.

O efeito do nível do gasto do governo sobre o crescimento per capita é positivo. Assim, aparentemente a produtividade do gasto do governo é maior do que o peso morto gerado pela tributação necessária para financiar este gasto. A relação é, entretanto, estatisticamente não significante.

A coluna (b) inclui no vetor de razões do gasto público, a parcela do gasto de capital no gasto total. Ela mostra uma relação positiva entre esta despesa e a taxa de crescimento do PIB per capita. O gasto público com capital aumenta o estoque físico de capital de um país, o que, a princípio, aumentaria a produtividade do setor privado e promoveria o crescimento. Entretanto, este variável não é estatisticamente significante.

Novamente, o nível do gasto do governo aparece com coeficiente positivo e estatisticamente não significante.

A coluna (c) inclui as parcelas do gasto de acordo com a classificação funcional. Gastos com defesa, educação, transporte e comunicação afetam positivamente a taxa de crescimento per capita e são estatisticamente significantes. Gastos com saúde também afetam positivamente a taxa de crescimento per capita, mas são estatisticamente insignificantes. Assim, quando se analisa o gasto público de acordo com a função do governo, observa-se claramente sua importância para o crescimento das economias estaduais. Ao garantir segurança pública, educação e infra-estrutura, os Estados propiciam um ambiente favorável para o desenvolvimento e a ampliação da atividade econômica por parte dos agentes privados, o que favorece o crescimento.

O efeito do nível do gasto do governo sobre o crescimento per capita é positivo e estatisticamente significante. Este resultado indica que, no caso dos Estados, a forma como a receita dos tributos é aplicada gera benefícios que superam a perda de eficiência causada pela imposição destes tributos sobre a atividade econômica.

Nas especificações (a), (b) e (c), praticamente todas as variáveis dummy de ano são estatisticamente significantes, indicando que existe um fator comum explicando a taxa de crescimento dos Estados.

\section{ESPECIFICAÇÕES ALTERNATIVAS}

A Tabela 4 apresenta os resultados da estimação de uma especificação não-linear do modelo. Tanto a teoria quanto a intuição sugerem que as razões do gasto e o crescimento devem ter uma relação não-linear. Os gastos produtivos podem estar positivamente associados com o crescimento quando suas parcelas no orçamento são pequenas, no entanto, esta relação torna-se negativa quando a parcela se torna grande. Isto porque à medida que a parcela aumenta, observam-se retornos decrescentes de escala e, eventualmente, a relação entre as duas variáveis se torna negativa. 
Tabela 4 - Composição do gasto do governo e crescimento econômico - Modelo de Efeito Fixo com especificação não-linear (erro padrão)

\begin{tabular}{|c|c|c|c|}
\hline Variáveis Explicativas & (a) & (b) & (c) \\
\hline DespesaTotal/PIB & $\begin{array}{c}0,033 \\
(0,029)\end{array}$ & $\begin{array}{c}0,033 \\
(0,028)\end{array}$ & $\begin{array}{c}0,065 \\
(0,026)^{* *}\end{array}$ \\
\hline Desp. Corrente Primária/Despesa Total & $\begin{array}{c}0,161 \\
(0,096)^{\star * *}\end{array}$ & & \\
\hline$\left(\right.$ Desp. Corrente Primária/Despesa Total) ${ }^{\wedge} 2$ & $\begin{array}{l}-0,131 \\
(0,072)^{\star * *}\end{array}$ & & \\
\hline Desp. Capital/Despesa Total & & $\begin{array}{c}0,083 \\
(0,046)^{* * *}\end{array}$ & \\
\hline (Desp. Capital/Despesa Total)^2 & & $\begin{array}{l}-0,116 \\
(0,069)^{* * *}\end{array}$ & \\
\hline Desp. Defesa/Despesa Total & & & $\begin{array}{l}-0,234 \\
(0,220)\end{array}$ \\
\hline Desp. Defesa/Despesa Total) ${ }^{\wedge} 2$ & & & $\begin{array}{c}3,599 \\
(1,553)^{\star *}\end{array}$ \\
\hline Desp. Educação/Despesa Total & & & $\begin{array}{c}0,475 \\
(0,136)^{*}\end{array}$ \\
\hline (Desp. Educação/Despesa Total)^2 & & & $\begin{array}{l}-1,096 \\
(0,402)^{*}\end{array}$ \\
\hline Desp. Saúde/Despesa Total & & & $\begin{array}{c}0,025 \\
(0,110)\end{array}$ \\
\hline (Desp. Saúde/DespesaTotal)^2 & & & $\begin{array}{l}-0,180 \\
(0,439)\end{array}$ \\
\hline Desp. Transporte e Comunicação/Despesa Total & & & $\begin{array}{c}0,202 \\
(0,064)^{*}\end{array}$ \\
\hline (Desp. Transporte e Comunicação/Despesa Total)^2 & & & $\begin{array}{l}-0,390 \\
(0,232)^{\star * *}\end{array}$ \\
\hline 1987 & $\begin{array}{l}-0,013 \\
(0,006)^{* *}\end{array}$ & $\begin{array}{l}-0,013 \\
(0,006)^{* *}\end{array}$ & $\begin{array}{l}-0,012 \\
(0,006)^{* *}\end{array}$ \\
\hline 1988 & $\begin{array}{l}-0,012 \\
(0,006)\end{array}$ & $\begin{array}{l}-0,012 \\
(0,006)\end{array}$ & $\begin{array}{l}-0,008 \\
(0,006)\end{array}$ \\
\hline 1989 & $\begin{array}{c}0,022 \\
(0,006)^{*}\end{array}$ & $\begin{array}{c}0,022 \\
(0,006)^{*}\end{array}$ & $\begin{array}{c}0,028 \\
(0,006)^{*}\end{array}$ \\
\hline 1990 & $\begin{array}{c}0,020 \\
(0,006)^{*}\end{array}$ & $\begin{array}{c}0,020 \\
(0,006)^{*}\end{array}$ & $\begin{array}{c}0,019 \\
(0,006)^{*}\end{array}$ \\
\hline 1991 & $\begin{array}{c}0,037 \\
(0,006)^{*}\end{array}$ & $\begin{array}{c}0,037 \\
(0,006)^{*}\end{array}$ & $\begin{array}{c}0,038 \\
(0,006)^{*}\end{array}$ \\
\hline 1992 & $\begin{array}{c}0,029 \\
(0,006)^{*}\end{array}$ & $\begin{array}{c}0,029 \\
(0,006)^{*}\end{array}$ & $\begin{array}{c}0,031 \\
(0,006)^{*}\end{array}$ \\
\hline 1993 & $\begin{array}{c}0,017 \\
(0,006)^{*}\end{array}$ & $\begin{array}{c}0,017 \\
(0,006)^{*}\end{array}$ & $\begin{array}{c}0,018 \\
(0,006)^{*}\end{array}$ \\
\hline 1994 & $\begin{array}{c}0,011 \\
(0,006)\end{array}$ & $\begin{array}{c}0,011 \\
(0,006)\end{array}$ & $\begin{array}{l}0,010 \\
(0,006)^{* * *}\end{array}$ \\
\hline 1995 & $\begin{array}{c}0,019 \\
(0,007)^{*}\end{array}$ & $\begin{array}{c}0,019 \\
(0,007)^{*}\end{array}$ & $\begin{array}{c}0,019 \\
(0,006)^{*}\end{array}$ \\
\hline 1996 & $\begin{array}{c}0,019 \\
(0,007)^{*}\end{array}$ & $\begin{array}{c}0,019 \\
(0,007)^{*}\end{array}$ & $\begin{array}{c}0,021 \\
(0,006)^{*}\end{array}$ \\
\hline 1997 & $\begin{array}{c}0,024 \\
(0,006)^{*}\end{array}$ & $\begin{array}{c}0,024 \\
(0,006)^{*}\end{array}$ & $\begin{array}{c}0,027 \\
(0,006)^{*}\end{array}$ \\
\hline 1998 & $\begin{array}{c}0,025 \\
(0,006)^{*}\end{array}$ & $\begin{array}{c}0,025 \\
(0,006)^{*}\end{array}$ & $\begin{array}{c}0,028 \\
(0,006)^{*}\end{array}$ \\
\hline Constante & $\begin{array}{c}0,938 \\
(0,035)^{*}\end{array}$ & $\begin{array}{c}0,973 \\
(0,010)^{*}\end{array}$ & $\begin{array}{c}0,914 \\
(0,016)^{*}\end{array}$ \\
\hline N. ${ }^{\circ}$ de Obs. & 347 & 347 & 347 \\
\hline
\end{tabular}

Nota: ${ }^{*}{ }^{* *} \mathrm{e}^{* *}$ significam que as variáveis são estatisticamente significantes aos níveis de $1 \%, 5 \%$ e $10 \%$ respectivamente. 
Na especificação (a), os resultados mostram que a taxa de crescimento é uma função crescente da parcela do gasto corrente primário e uma função decrescente dessa variável ao quadrado, e ambos os coeficientes são estatisticamente significantes. Ainda que esses coeficientes sejam estatisticamente significantes somente ao nível de $10 \%$, pode-se dizer que a relação existente entre gasto corrente e crescimento é não-linear. Consoante às evidências apresentadas por Devarajan et al. (1996), para os países em desenvolvimento, o gasto corrente está associado a um maior crescimento econômico, mas, no caso dos Estados brasileiros, existe um limite para este efeito. De acordo com os parâmetros estimados, este limite seria de aproximadamente $61 \%$. Acima deste limite o gasto corrente apresenta um efeito negativo sobre o crescimento per capita e pode ser considerado improdutivo. Com exceção de Tocantins, todos os demais Estados tiveram uma fração média do gasto corrente superior a esse limite (Tabela 1) no período 1986-2003. Não é surpreendente, então, que na especificação linear (Tabela 3) este gasto apareça como improdutivo, mas não significante.

No que diz respeito à variável gasto com capital como parcela do gasto total, a sua especificação não-linear é apresentada na coluna (b). Também para esta variável, o modelo estimado capta uma relação não-linear com o crescimento per capita. O coeficiente associado à parcela do gasto com capital é positivo, esta variável ao quadrado possui coeficiente negativo, e ambos são estatisticamente significantes. O limite para este gasto é de aproximadamente $36 \%$ e, no período analisado, apenas o Estado de Tocantins superou este valor (Tabela 1). Novamente, não é surpreendente que, na especificação linear (Tabela 3), o gasto com capital apareça como produtivo, embora não significante.

Finalmente, na especificação (c) os gastos com educação apresentam claramente efeitos nãolineares. Esta variável apresenta coeficiente positivo e o seu termo quadrático coeficiente negativo, sendo ambos estatisticamente significantes. Isso sugere que existe um limite máximo ótimo para a parcela da despesa pública que deve ser destinada ao gasto com educação. De acordo com os parâmetros estimados, este limite seria de aproximadamente $22 \%$. No período analisado, nenhum Estado apresentou uma média da parcela do gasto com educação acima desse valor.

Embora com evidência mais fraca, os gastos com transporte e comunicação também apresentam um efeito não-linear, uma vez que esta variável aparece com sinal positivo e significante a $1 \%$, e o termo quadrático com sinal negativo, mas significante somente a $10 \%$. Este gasto passa a ser improdutivo quando ele representa uma parcela superior a $26 \%$ da despesa total do governo. Novamente, no período 1986-2003, nenhum Estado apresentou uma média da parcela do gasto com transporte e comunicação acima desse valor.

O modelo teórico de Devarajan et al. (1996) implica que gastos aparentemente produtivos podem se tornar improdutivos se são feitos em excesso. Os autores mostram que esse é o caso dos países em desenvolvimento, mas não dos países desenvolvidos. Os países em desenvolvimento alocaram de forma errada os gastos públicos, privilegiando os gastos em capital em detrimento dos gastos correntes, enquanto os países desenvolvidos fizeram o contrário. Assim, os excessivos gastos em capital nos países em desenvolvimento os tornaram não produtivos na margem. Por sua vez, os gastos correntes relativamente desprezados se tornaram produtivos na margem.

A fim de verificar se existiria um comportamento diferente do gasto público entre os diversos Estados, uma vez que aqui se trabalha com um conjunto de Estados desenvolvidos e outros menos

17 A especificação deste modelo linear pode ser escrita como $Y_{i t}=a_{i}+g_{t}+\beta^{\prime} X_{i t}+\gamma^{\prime}\left(X^{\prime} X\right)+u_{i t}$. Assim, para uma variável $x_{j}$ específica, seu efeito máximo é dado pelo ponto $\frac{\partial Y}{\partial x_{j}}=\beta_{j}+2 \gamma_{j} x_{j}=0 \Rightarrow x_{j}=-\frac{\beta_{j}}{2 \gamma_{j}}$ 
desenvolvidos, reestimou-se o modelo apresentado na Seção 4.1 para os dois grupos de Estados separadamente. A Tabela 5 apresenta os resultados para os Estados mais desenvolvidos (São Paulo, Rio de Janeiro, Minas Gerais, Rio Grande do Sul, Santa Catarina e Paraná) e a Tabela 6 para os demais Estados, considerados menos desenvolvidos.

Tabela 5 - Composição do gasto do governo e crescimento econômico nos Estados desenvolvidos - Modelo LSDV (erro padrão)

\begin{tabular}{|c|c|c|c|}
\hline Variáveis Explicativas & (a) & (b) & (c) \\
\hline Despesa Total/PIB & $\begin{array}{l}-0,203 \\
(0,096)^{* *}\end{array}$ & $\begin{array}{l}-0,150 \\
(0,090)^{\star *}\end{array}$ & $\begin{array}{l}-0,129 \\
(0,086)\end{array}$ \\
\hline $\begin{array}{l}\text { Desp. Corrente Primária/ } \\
\text { Despesa Total }\end{array}$ & $\begin{array}{l}-0,066 \\
(0,029)^{\star *}\end{array}$ & & \\
\hline Desp. Capital/Despesa Total & & $\begin{array}{l}0,044 \\
(0,025)^{\star * *}\end{array}$ & \\
\hline Desp. Defesa/Despesa Total & & & $\begin{array}{l}-0,096 \\
(0,169)\end{array}$ \\
\hline Desp. Educação/Despesa Total & & & $\begin{array}{l}-0,012 \\
(0,073)\end{array}$ \\
\hline Desp. Saúde/Despesa Total & & & $\begin{array}{l}-0,039 \\
(0,066)\end{array}$ \\
\hline Desp. Transporte e Comunicação/Despesa Total & & & $\begin{array}{l}0,091 \\
(0,047)^{\star * \star}\end{array}$ \\
\hline 1987 & $\begin{array}{l}-0,008 \\
(0,007)\end{array}$ & $\begin{array}{l}-0,007 \\
(0,007)\end{array}$ & $\begin{array}{l}-0,005 \\
(0,007)\end{array}$ \\
\hline 1988 & $\begin{array}{l}-0,024 \\
(0,007)^{*}\end{array}$ & $\begin{array}{l}-0,023 \\
(0,007)^{*}\end{array}$ & $\begin{array}{l}-0,020 \\
(0,007)^{*}\end{array}$ \\
\hline 1989 & $\begin{array}{c}0,027 \\
(0,007)^{*}\end{array}$ & $\begin{array}{c}0,026 \\
(0,007)^{*}\end{array}$ & $\begin{array}{c}0,032 \\
(0,008)^{*}\end{array}$ \\
\hline 1990 & $\begin{array}{c}0,049 \\
(0,007)^{*}\end{array}$ & $\begin{array}{c}0,046 \\
(0,007)^{*}\end{array}$ & $\begin{array}{c}0,049 \\
(0,007)^{*}\end{array}$ \\
\hline 1991 & $\begin{array}{c}0,047 \\
(0,007)^{*}\end{array}$ & $\begin{array}{c}0,044 \\
(0,007)^{*}\end{array}$ & $\begin{array}{c}0,050 \\
(0,008)^{*}\end{array}$ \\
\hline 1992 & $\begin{array}{c}0,042 \\
(0,007)^{*}\end{array}$ & $\begin{array}{c}0,039 \\
(0,007)^{*}\end{array}$ & $\begin{array}{c}0,046 \\
(0,008)^{*}\end{array}$ \\
\hline 1993 & $\begin{array}{c}0,023 \\
(0,007)^{*}\end{array}$ & $\begin{array}{c}0,021 \\
(0,007)^{*}\end{array}$ & $\begin{array}{c}0,026 \\
(0,008)^{*}\end{array}$ \\
\hline 1994 & $\begin{array}{c}0,020 \\
(0,007)^{*}\end{array}$ & $\begin{array}{c}0,017 \\
(0,007)^{*}\end{array}$ & $\begin{array}{c}0,021 \\
(0,007)^{*}\end{array}$ \\
\hline 1995 & $\begin{array}{c}0,027 \\
(0,008)^{*}\end{array}$ & $\begin{array}{c}0,022 \\
(0,008)^{*}\end{array}$ & $\begin{array}{c}0,028 \\
(0,009)^{*}\end{array}$ \\
\hline 1996 & $\begin{array}{c}0,024 \\
(0,008)^{*}\end{array}$ & $\begin{array}{c}0,019 \\
(0,007)^{*}\end{array}$ & $\begin{array}{c}0,025 \\
(0,008)^{*}\end{array}$ \\
\hline 1997 & $\begin{array}{c}0,023 \\
(0,008)^{*}\end{array}$ & $\begin{array}{l}0,020 \\
(0,008)^{*}\end{array}$ & $\begin{array}{c}0,028 \\
(0,010)^{*}\end{array}$ \\
\hline 1998 & $\begin{array}{l}0,029 \\
(0,008)^{*}\end{array}$ & $\begin{array}{l}0,025 \\
(0,008)^{*}\end{array}$ & $\begin{array}{l}0,034 \\
(0,009)^{*}\end{array}$ \\
\hline Constante & $\begin{array}{c}1,053 \\
(0,029)^{*}\end{array}$ & $\begin{array}{c}0,991 \\
(0,009)^{*}\end{array}$ & $\begin{array}{c}0,998 \\
(0,027)^{*}\end{array}$ \\
\hline N. ${ }^{\circ}$ de Obs. & 78 & 78 & 78 \\
\hline
\end{tabular}

Nota: ${ }^{*},{ }^{*} \mathrm{e}{ }^{* *}$ significam que as variáveis são estatisticamente significantes aos níveis de $1 \%, 5 \%$ e $10 \%$, respectivamente. 
No caso dos Estados mais desenvolvidos, os gastos correntes afetam negativamente a taxa de crescimento da economia, enquanto que os gastos com capital possuem efeito positivo sobre a variável dependente, e esses resultados são estatisticamente significantes. Em relação às despesas funcionais, os gastos com transporte e comunicação mantiveram o resultado anterior e apresentaram efeito positivo sobre a taxa de crescimento per capita. No entanto, os gastos com defesa, educação e saúde apresentam agora coeficientes negativos, embora não significantes.

Tabela 6 - Composição do gasto do governo e crescimento econômico nos Estados menos desenvolvidos - Modelo LSDV (erro padrão)

\begin{tabular}{|c|c|c|c|}
\hline Variáveis Explicativas & (a) & (b) & (c) \\
\hline Despesa Total/PIB & $\begin{array}{c}0,033 \\
(0,032)\end{array}$ & $\begin{array}{c}0,033 \\
(0,031)\end{array}$ & $\begin{array}{c}0,088 \\
(0,029)^{*}\end{array}$ \\
\hline $\begin{array}{l}\text { Desp. Corrente Primária/ } \\
\text { Despesa Total }\end{array}$ & $\begin{array}{l}-0,021 \\
(0,023)\end{array}$ & & \\
\hline Desp. Capital/Despesa Total & & $\begin{array}{c}0,024 \\
(0,022)\end{array}$ & \\
\hline Desp. Defesa/Despesa Total & & & $\begin{array}{c}0,281 \\
(0,102)^{*}\end{array}$ \\
\hline Desp. Educação/Despesa Total & & & $\begin{array}{c}0,113 \\
(0,035)^{*}\end{array}$ \\
\hline Desp. Saúde/Despesa Total & & & $\begin{array}{l}0,018 \\
(0,046)\end{array}$ \\
\hline Desp. Transporte e Comunicação/Despesa Total & & & $\begin{array}{l}0,127 \\
(0,035)^{\star}\end{array}$ \\
\hline 1987 & $\begin{array}{l}-0,016 \\
(0,008)^{\star *}\end{array}$ & $\begin{array}{l}-0,015 \\
(0,008)^{\star * *}\end{array}$ & $\begin{array}{l}-0,012 \\
(0,007)^{\star * *}\end{array}$ \\
\hline 1988 & $\begin{array}{l}-0,010 \\
(0,008)\end{array}$ & $\begin{array}{l}-0,010 \\
(0,008)\end{array}$ & $\begin{array}{l}-0,003 \\
(0,008)\end{array}$ \\
\hline 1989 & $\begin{array}{c}0,020 \\
(0,008)^{*}\end{array}$ & $\begin{array}{c}0,020 \\
(0,008)^{*}\end{array}$ & $\begin{array}{c}0,028 \\
(0,008)^{*}\end{array}$ \\
\hline 1990 & $\begin{array}{l}0,013 \\
(0,008)^{\star * *}\end{array}$ & $\begin{array}{l}0,014 \\
(0,008)^{* * *}\end{array}$ & $\begin{array}{l}0,016 \\
(0,007)^{\star *}\end{array}$ \\
\hline 1991 & $\begin{array}{l}0,035 \\
(0,008)^{*}\end{array}$ & $\begin{array}{c}0,036 \\
(0,008)^{*}\end{array}$ & $\begin{array}{l}0,040 \\
(0,007)^{\star}\end{array}$ \\
\hline 1992 & $\begin{array}{c}0,027 \\
(0,008)^{*}\end{array}$ & $\begin{array}{c}0,027 \\
(0,008)^{*}\end{array}$ & $\begin{array}{c}0,030 \\
(0,007)^{*}\end{array}$ \\
\hline 1993 & $\begin{array}{l}0,016 \\
(0,008)^{\star \star}\end{array}$ & $\begin{array}{l}0,017 \\
(0,008)^{* *}\end{array}$ & $\begin{array}{c}0,019 \\
(0,007)^{*}\end{array}$ \\
\hline 1994 & $\begin{array}{c}0,011 \\
(0,008)\end{array}$ & $\begin{array}{c}0,011 \\
(0,008)\end{array}$ & $\begin{array}{c}0,010 \\
(0,007)\end{array}$ \\
\hline 1995 & $\begin{array}{c}0,019 \\
(0,009)^{* *}\end{array}$ & $\begin{array}{l}0,020 \\
(0,008)^{* *}\end{array}$ & $\begin{array}{l}0,019 \\
(0,007)^{* *}\end{array}$ \\
\hline 1996 & $\begin{array}{l}0,021 \\
(0,008)^{\star *}\end{array}$ & $\begin{array}{l}0,021 \\
(0,008)^{* *}\end{array}$ & $\begin{array}{c}0,023 \\
(0,007)^{\star}\end{array}$ \\
\hline 1997 & $\begin{array}{c}0,027 \\
(0,008)^{*}\end{array}$ & $\begin{array}{c}0,028 \\
(0,008)^{*}\end{array}$ & $\begin{array}{c}0,030 \\
(0,007)^{*}\end{array}$ \\
\hline 1998 & $\begin{array}{l}0,028 \\
(0,008)^{*}\end{array}$ & $\begin{array}{c}0,028 \\
(0,008)^{*}\end{array}$ & $\begin{array}{l}0,030 \\
(0,007)^{*}\end{array}$ \\
\hline Constante & $\begin{array}{c}1,000 \\
(0,020)^{*}\end{array}$ & $\begin{array}{c}0,979 \\
(0,009)^{*}\end{array}$ & $\begin{array}{c}0,921 \\
(0,015)^{*}\end{array}$ \\
\hline N. ${ }^{\circ}$ de Obs & 269 & 269 & 269 \\
\hline
\end{tabular}

Nota: ${ }^{*},{ }^{*} \mathrm{e}{ }^{* *}$ significam que as variáveis são estatisticamente significantes aos níveis de $1 \%, 5 \%$ e $10 \%$, respectivamente. 
O efeito do nível do gasto do governo sobre o crescimento econômico, captado pela parcela da despesa orçamentária em relação ao PIB, é o resultado que mais se destaca. Para o conjunto dos Estados este efeito é positivo. Contudo, quando apenas os Estados mais desenvolvidos são analisados, observa-se que o efeito torna-se negativo e significante. Isto indica que, para estes Estados, a produtividade do gasto público é menor do que o peso morto gerado pelo montante de impostos necessários para financiá-lo.

No que diz respeito aos Estados menos desenvolvidos, os resultados qualitativos são os mesmos do modelo estimado para toda a amostra. Os gastos correntes primários apresentam coeficiente negativo, indicando que um aumento deste item reduz o crescimento per capita. Os gastos com capital possuem efeito positivo, contribuindo, portanto, para o aumento do produto. Entretanto, ambos os coeficientes são não significantes do ponto de vista estatístico (colunas a e b). A parcela do gasto total sobre o PIB e os gastos com defesa, educação, transporte e comunicação possuem efeito positivo sobre o crescimento do PIB per capita e estes são estatisticamente significantes (coluna c).

Assim, não parece haver indício de que nos Estados menos desenvolvidos as parcelas iniciais dos gastos tradicionalmente considerados produtivos sejam já bastante elevadas de forma que aumentos nesses gastos tornem os mesmos improdutivos.

Como teste para a robustez dos resultados, incluíram-se nas regressões outras variáveis que em estudos anteriores sobre crescimento apareceram como importantes. A primeira é a população economicamente ativa (PEA) e a segunda o investimento privado.

A inclusão da variável explicativa população economicamente ativa não alterou os resultados qualitativos do modelo (ver Tabela A1 anexa). Os gastos correntes primários continuam com efeito negativo sobre a variável dependente, e os gastos com capital afetam positivamente o produto, ambos estatisticamente insignificantes. Os resultados do modelo que inclui a classificação funcional das despesas também são bastante robustos. Os gastos com defesa, educação e transporte e comunicação afetam positivamente a taxa de crescimento, e estes resultados são estatisticamente significantes. A influência dos gastos com saúde sobre o crescimento do PIB permanece positiva, porém este coeficiente não é significante do ponto de vista estatístico. Em todas as especificações, a PEA apresenta coeficiente negativo, mas estatisticamente insignificante.

No que diz respeito ao investimento privado, Mazoni (2005), afirma que este tem uma relação de longo prazo positiva com o produto. Embora ela não encontre relação entre o investimento privado e o investimento público, outros trabalhos como Sant'ana, Rocha e Teixeira (1994), por sua vez, encontram indicações de que há complementariedade entre eles. ${ }^{18}$ Assim, a inclusão do investimento privado no modelo viria a controlar uma possível relação entre as duas modalidades de investimento e entre esses investimentos e o produto.

Entretanto, como o objetivo do trabalho é estudar os efeitos da política fiscal dos Estados brasileiros sobre o seu produto, esbarra-se na falta de dados sobre o montante de investimento privado realizado em cada Estado. Para contornar o problema, foi utilizado como proxy para o investimento privado o montante da formação bruta de capital fixo (FBCF) em construções, calculado por Silveira (2005). ${ }^{19}$ Como a série de FBCF em construções foi calculada a partir de 1991, a amostra utilizada na estimação do modelo abrange o período de 1991 a 1998. Os resultados são apresentados na Tabela 7 a seguir.

18 Como mencionado na nota 9, os diversos trabalhos que analisam a relação investimentos públicos e investimentos privados no Brasil trazem evidências distintas sem chegar a uma conclusão.

19 Para maiores detalhes sobre a metodologia utilizada na construção da série ver Apêndice 1, de Silveira (2005). 
Tabela 7 - Composição do gasto do governo e crescimento econômico, com controle para investimento privado - Modelo LSDV (erro padrão)

\begin{tabular}{|c|c|c|c|}
\hline Variáveis Explicativas & (a) & (b) & (c) \\
\hline Despesa Total/PIB & $\begin{array}{l}-0,007 \\
(0,036)\end{array}$ & $\begin{array}{l}-0,010 \\
(0,035)\end{array}$ & $\begin{array}{c}0,035 \\
(0,033)\end{array}$ \\
\hline Desp. Corrente Primária/Despesa Total & $\begin{array}{l}-0,023 \\
(0,021)\end{array}$ & & \\
\hline Desp.Capital/Despesa Total & & $\begin{array}{c}0,030 \\
(0,020)\end{array}$ & \\
\hline Desp. Defesa/Despesa Total & & & $\begin{array}{c}0,218 \\
(0,099)^{* *}\end{array}$ \\
\hline Desp. Educação/Despesa Total & & & $\begin{array}{c}0,074 \\
(0,042)^{\star * *}\end{array}$ \\
\hline Desp. Saúde/Despesa Total & & & $\begin{array}{c}0,115 \\
(0,055)^{\star *}\end{array}$ \\
\hline Desp. Transporte e Comunicação/Despesa Total & & & $\begin{array}{c}0,111 \\
(0,035)^{*}\end{array}$ \\
\hline Investimento privado & $\begin{array}{c}0,001 \\
(0,0003)^{*}\end{array}$ & $\begin{array}{c}0,001 \\
(0,0003)^{*}\end{array}$ & $\begin{array}{c}0,001 \\
(0,0003)^{* *}\end{array}$ \\
\hline 1992 & $\begin{array}{l}-0,007 \\
(0,005)\end{array}$ & $\begin{array}{l}-0,007 \\
(0,005)\end{array}$ & $\begin{array}{l}-0,008 \\
(0,005)\end{array}$ \\
\hline 1993 & $\begin{array}{l}-0,021 \\
(0,005)^{*}\end{array}$ & $\begin{array}{l}-0,021 \\
(0,005)^{*}\end{array}$ & $\begin{array}{l}-0,022 \\
(0,005)^{*}\end{array}$ \\
\hline 1994 & $\begin{array}{l}-0,027 \\
(0,005)^{*}\end{array}$ & $\begin{array}{l}-0,027 \\
(0,005)^{*}\end{array}$ & $\begin{array}{l}-0,029 \\
(0,005)^{*}\end{array}$ \\
\hline 1995 & $\begin{array}{l}-0,019 \\
(0,005)^{*}\end{array}$ & $\begin{array}{l}-0,019 \\
(0,005)^{*}\end{array}$ & $\begin{array}{l}-0,019 \\
(0,005)^{*}\end{array}$ \\
\hline 1996 & $\begin{array}{l}-0,019 \\
(0,005)^{*}\end{array}$ & $\begin{array}{l}-0,018 \\
(0,005)^{*}\end{array}$ & $\begin{array}{l}-0,016 \\
(0,005)^{*}\end{array}$ \\
\hline 1997 & $\begin{array}{l}-0,017 \\
(0,005)^{*}\end{array}$ & $\begin{array}{l}-0,017 \\
(0,005)^{*}\end{array}$ & $\begin{array}{l}-0,012 \\
(0,005)^{*}\end{array}$ \\
\hline 1998 & $\begin{array}{l}-0,013 \\
(0,005)^{* *}\end{array}$ & $\begin{array}{l}-0,013 \\
(0,005)^{* *}\end{array}$ & $\begin{array}{l}-0,009 \\
(0,005)^{* * *}\end{array}$ \\
\hline Constante & $\begin{array}{c}1,037 \\
(0,020)^{*}\end{array}$ & $\begin{array}{c}1,014 \\
(0,008)^{*}\end{array}$ & $\begin{array}{c}0,969 \\
(0,015)^{*}\end{array}$ \\
\hline $\mathrm{N}^{0}$ de Obs. & 216 & 216 & 216 \\
\hline
\end{tabular}

Nota: ${ }^{*}{ }^{* *} \mathrm{e}^{* * *}$ significam que as variáveis são estatisticamente significantes aos níveis de $1 \%, 5 \%$ e $10 \%$, respectivamente.

Em todas as especificações do modelo, (a), (b) e (c), os resultados apresentados confirmam a relação esperada entre o investimento privado e a taxa de crescimento do produto. $\mathrm{O}$ coeficiente estimado é positivo e estatisticamente significante.

No que tange às demais variáveis, os resultados qualitativos se mantiveram. A parcela do gasto corrente primário, na coluna (a), e a parcela a parcela do gasto com capital, na coluna (b), apresentam coeficientes negativo e positivo, respectivamente, e não são estatisticamente significantes. Os gastos com transporte e comunicação, educação e defesa, na coluna (c), possuem efeito positivo sobre a variação do PIB per capita, e são estatisticamente significantes. Já o gasto com saúde apresenta coeficiente positivo, que, neste modelo, é significante do ponto de vista estatístico. 


\section{CONCLUSÕES}

No que diz respeito à relação entre composição dos gastos e crescimento econômico dos Estados brasileiros no longo prazo, tem-se o seguinte diagnóstico:

- A relação entre gastos com defesa, educação, transporte e comunicação com o crescimento econômico é positiva.

- A relação entre os gastos com capital e a taxa de crescimento é positiva e aparentemente nãolinear.

- A relação entre os gastos correntes primários do governo e o crescimento econômico é aparentemente positiva e não-linear.

Tem-se, dessa forma, que todos os candidatos padrão da literatura para gasto produtivo - capital, educação, transporte e comunicação - têm um efeito positivo e estatisticamente significante sobre o crescimento. A única exceção é a saúde, que aparece com sinal positivo, mas não significante.

A existência de um efeito positivo, porém não-linear, dos gastos em consumo sobre o crescimento de longo prazo sugere, a princípio, que este tipo de gasto não é tão prejudicial à economia como se argumenta. Entretanto, o efeito não-linear mostra claramente que existe um limite para o aumento deste tipo de gasto e que esse limite - $61 \%$ da despesa orçamentária - já foi ultrapassado por todos os Estados, com exceção de Tocantins. Isto leva à necessidade de reorientação na composição dos gastos em direção aos gastos com investimento, uma vez que esses têm um efeito positivo sobre o produto.

Ainda que se encontre evidência de que também há um limite para o efeito positivo do gasto com capital sobre o crescimento, todos os Estados - com exceção de Tocantins - ainda gastam abaixo deste limite. Além do mais, cortes no investimento devem ser evitados porque caracterizam consolidações fiscais malsucedidas (cortes nesse item têm caráter temporário) e essas, em geral, não levam à expansão da economia. Desta forma, um corte nos gastos em consumo ao invés de um corte nos gastos em investimento, traria um benefício adicional de estímulo à economia no curto prazo.

É importante lembrar ainda que setores tipicamente de responsabilidade do governo, por terem um elevado risco associado e/ou horizonte temporal longo para amortização dos recursos investidos, são pouco atrativos ao capital privado. No entanto, o governo, diante de restrições fiscais severas, se vê obrigado a adiar investimentos prioritários. A questão é como alterar o ambiente institucional de forma a aumentar a disponibilidade de recursos destinados a áreas pouco atrativas ao capital privado.

Finalmente, na literatura existem indicações de que países com maior transparência e hierarquia na execução orçamentária produzem melhores resultados em termos de gasto público (ver Amorim Neto e Borsani, 2002). O índice das instituições orçamentárias desenvolvido por Alesina et al. (1999) para medir o controle orçamentário em 20 países da América Latina e Caribe indica, contudo, que o Brasil só apresenta um desempenho melhor do que três outros países. Assim, uma melhora na condução da peça orçamentária dos Estados poderia implicar um melhor comportamento fiscal agregado.

Deve-se ter em mente que a avaliação macroeconômica da qualidade do gasto público é, contudo, insuficiente. Ainda que gastos com educação (e eventualmente saúde) apareçam como promotores do crescimento, é de fundamental importância uma avaliação microeconômica desses gastos. Assim, por exemplo, uma avaliação dos programas sociais do governo seria de extrema ajuda. Em caso de um diagnóstico de ineficiência (superposição com outros programas ou resultados inexpressivos ou contraditórios), esses programas deveriam ser abandonados completamente ou 
substituídos por outros. Somente desta maneira ter-se-ia uma idéia precisa do grau de qualidade e eficiência dos gastos públicos.

\section{REFERÊNCIAS BILBLIOGRÁFICAS}

AFONSO, A., EBERT, W., SCHUKNECHT, L., THONE, M. Quality of public finances and growth. European Central Bank, Feb. 2005. ( Working Paper Seires, n. 438).

ALESINA, A.; ARDAGNA, S. Tales of fiscal adjustments. Economic Policy, v. 27, , p. 489-545, Outubro,1998.

.; HAUSMANN, R.; HOMMES, R.; STEIN, E. Budget institutions and fiscal performance in Latin America. Journal of Development Economics, v. 59, p. 253-273, 1999.

.; PEROTTI, R. Fiscal expansions and fiscal adjustments in OECD countries. Economic Policy, v. 21, Oct. 1995.

. Fiscal adjustments in OECD countries: composition and macroeconomic effects. IMF Staff Papers, v. 44, n. 2, p. 210-248, jun. 1997.

AMORIM NETO, O.; BORSANI, H. Os determinantes políticos do comportamento fiscal na América Latina. IPEA, 2002. (Seminários DIMAC n. 123).

ASCHAUER, D. Is public expenditure productive? Journal of Monetary Economics, v. 23, p. 177-200, 1989.

.; GREENWOOD, J. Macroeconomic effects of fiscal policy. Carnegie-Rochester Series on Public Policy 23, p. 91-138, 1985.

ASSIS, L. ; DIAS, J. Política fiscal, nível tecnológico e crescimento econômico no Brasil: teoria e evidência empírica In: XXXII ENCONTRO NACIONAL DE ECONOMIA, 2004, João Pessoa.

BARRO, R. J. Government spending in a simple model of endogenous growth. Journal of Political Economy, v. 98, p. 103-125, 1990.

. Economic growth in a cross-section of countries. The Quarterly Journal of Economics 106, p. 407-444, 1991.

BERTOLA, G.; DRAZEN, A. Trigger points and budget cuts: explaining the effects of fiscal austerity. American Economic Review, v. 83, p. 11-26, Mar. 1993

BRASIL. Constituição (1988). Constituição da República Federativa do Brasil. Brasília: Senado Federal, 1988.

CÂNDIDO JR., J. Os gastos públicos no Brasil são produtivos? IPEA, 2001. (Texto para Discussão $\mathrm{n}^{\circ}$. 781).

DEVARAJAN, S.; SWARROP, V.; ZOU, H. The composition of public expenditure and economic growth. Journal of Monetary Economics, v. 37, p. 313-344, 1996.

EASTERLY, W.; REBELO, S. Fiscal policy and economic growth: an empirical investigation. Journal of Monetary Economics, v. 32, p. 417-458, 1993.

FELDSTEIN, M. Government deficits and aggregate demand. Journal of Monetary Economics. v. 9, n. 1, p.1-20, Jan. 1982.

FERREIRA, P. C. Investimento em infra-estrutura no Brasil: fatos estilizados e relações de longo prazo. Pesquisa e Planejamento Econômico, v. 26, n. 2, p. 231-252, 1996.

.; MALLIAGROS, T. G. Impactos produtivos da infra-estrutura no Brasil - 1950/95. Pesquisa è Planejamento Econômico, v. 28 n. 2, p. 315-338, 1998.

GIAVAZZI, F; PAGANO, M. Can severe fiscal contractions be expansionary: tales of two small European countries. In: NBER Macroeconomics Annual 1990. Cambridge, Massachussets: MIT Press, p. 75-111, 1990. 
. Non-keynesian effects of fiscal policy changes: international evidence and the Swedish experience. 1995. (NBER Working paper n. 5332).

GRIER, K.; TULLOCK, G. An empirical analysis of cross-national economic growth, 1951-1980. Journal of Monetary Economics, v. 24, p. 259-276, 1989.

HERRERA, S.; BLANCO, F. The quality of fiscal adjustment and the long run growth impact of fiscal policy in Brazil. 2004. Mimeo.

HOLTZ-EAKIN, D. Public-sector capital and the productivity puzzle. Syracuse, NY: Syracuse University, 1991. Mimeo.

KNELLER, R.; BLEANEY, M. F.; GEMMELL, N. Growth, public policy and the government budget constraint: evidence form OECD countries. Nottingham: School of Economics, University of Nottingham, 1998. (Discussion paper n. 98/14).

KNELLER, R.; BLEANEY, M. F.; GEMMELL, N. Fiscal policy and growth: evidence from OECD countries. Journal of Public Economics, v. 74, p. 171-190, 1999.

KORMENDI, R. C.; MEGUIRE, P. G. Macroeconomic determinants of growth. Journal of Monetary Econometrics. v. 16, p. 141-163, 1985.

LINDAUER, D. L.; VELENCHIK, A. D. Government spending in developing countries: trends, causes and determinants. World Bank Research Observer, v. 7, p. 59-78, 1992.

LLEDÓ, V. D.; FERREIRA, P. C. Crescimento endógeno, distribuição de renda e política fiscal: uma análise cross-section para os Estados brasileiros. Pesquisa e Planejamento Econômico, v. 27 n. 1, p. 4170, 1997.

MAZONI, M. G. Gastos públicos e crescimento econômico no Brasil: análise dos impactos dos gastos com custeio e investimento. Dissertação (Mestrado) - FEA/USP, São Paulo, 2005.

MCDERMOTT, J.; WESCOTT, R. F. An empirical analysis of fiscal adjustments. IMF Staff Papers, v. 43, n. 4, p. 725-753, Dec. 1996.

MORRISON, C.; SCHWARTZ, A. E. State infrastructure and productive performance. Medford, MA: Tufts University, 1991. Mimeo.

PEROTTI, R. Fiscal policy in good times and bad. The Quarterly Journal of Economics, v. 114, n. 4, p. 1399-1436, Nov. 1999.

ROCHA, C .H.; TEIXEIRA, J. R. Complementaridade versus substituição entre investimento público e privado na economia brasileira: 1965-1990. Revista Brasileira de Economia, v. 50, n. 3, p. 378-384, 1996.

RONCI, M. V. Uma nota sobre a especificação da função de investimento agregado para países em desenvolvimento. Revista Brasileira de Economia, v. 42, n. 2, p. 179-194, 1991.

SANT'ANNA, T.; ROCHA, C. H.; TEIXEIRA, J. R. The impacto of public investment on private capital formation in Brazil: 1965-1985. In: BRAZILIAN MEETING OF OPERATIONAL RESEARCH PROCEEDINGS, 1994.

SILVEIRA, A. C. B. de M. Determinantes dos investimentos privados: evidência empírica para os Estados brasileiros na década de 1990. Dissertação (Mestrado) - Departamento de Economia, Administração e Contabilidade da Universidade de São Paulo, 2005.

SOUZA JR., J. R.; JAYME JR., F. G. Constrangimentos ao crescimento no Brasil. Um modelo de hiatos (1970-2000). Revista de Economia Contemporânea. v. 8, n. 1, p. 33-65, 2004.

SUMMERS, R.; HESTON, A. A new set of international comparisons of real product and price levels. Estimates for 130 countries. Review of Income and Wealth, v. 34, p. 1-25, 1988.

SUTHERLAND, A. Fiscal crises and aggregate demand: can high public debt reverse the effects of fiscal policy? Journal of Public Economics, v. 65, n. 2, Aug. 1997. 


\section{ANEXo}

Tabela A1 - Composição do gasto do governo e crescimento econômico, com controle para PEA - Modelo LSDV (erro padrão)

\begin{tabular}{|c|c|c|c|}
\hline Variáveis Explicativas & (a) & (b) & (c) \\
\hline Despesa Total/PIB & $\begin{array}{c}0,033 \\
(0,030)\end{array}$ & $\begin{array}{c}0,035 \\
(0,029)\end{array}$ & $\begin{array}{l}0,072 \\
(0,028)^{*}\end{array}$ \\
\hline $\begin{array}{l}\text { Desp. Corrente Primária/ } \\
\text { Despesa Total }\end{array}$ & $\begin{array}{l}-0,020 \\
(0,019)\end{array}$ & & \\
\hline Desp. Capital/Despesa Total & & $\begin{array}{c}0,021 \\
(0,018)\end{array}$ & \\
\hline Desp. Defesa/Despesa Total & & & $\begin{array}{c}0,264 \\
(0,089)^{*}\end{array}$ \\
\hline Desp. Educação/Despesa Total & & & $\begin{array}{c}0,115 \\
(0,031)^{*}\end{array}$ \\
\hline Desp. Saúde/Despesa Total & & & $\begin{array}{c}0,011 \\
(0,040)\end{array}$ \\
\hline Desp. Transporte e Comunicação/Despesa Total & & & $\begin{array}{l}0,127 \\
(0,031)^{\star}\end{array}$ \\
\hline PEA & $\begin{array}{l}-0,00000001 \\
(0,000000004)\end{array}$ & $\begin{array}{l}-0,00000001 \\
(0,000000004)\end{array}$ & $\begin{array}{l}-0,0000000001 \\
(0,000000004)\end{array}$ \\
\hline 1987 & $\begin{array}{l}-0,013 \\
(0,006)^{* *}\end{array}$ & $\begin{array}{l}-0,012 \\
(0,006)^{* *}\end{array}$ & $\begin{array}{l}-0,010 \\
(0,006)^{\star * *}\end{array}$ \\
\hline 1988 & $\begin{array}{l}-0,011 \\
(0,006)^{* * *}\end{array}$ & $\begin{array}{l}-0,011 \\
(0,006)^{\star * *}\end{array}$ & $\begin{array}{l}-0,006 \\
(0,006)\end{array}$ \\
\hline 1989 & $\begin{array}{l}0,023 \\
(0,006)^{*}\end{array}$ & $\begin{array}{c}0,023 \\
(0,006)^{*}\end{array}$ & $\begin{array}{c}0,030 \\
(0,006)^{*}\end{array}$ \\
\hline 1990 & $\begin{array}{c}0,023 \\
(0,006)^{*}\end{array}$ & $\begin{array}{c}0,023 \\
(0,006)^{*}\end{array}$ & $\begin{array}{l}0,022 \\
(0,006)^{*}\end{array}$ \\
\hline 1991 & $\begin{array}{c}0,039 \\
(0,007)^{*}\end{array}$ & $\begin{array}{c}0,039 \\
(0,006)^{*}\end{array}$ & $\begin{array}{c}0,042 \\
(0,006)^{*}\end{array}$ \\
\hline 1992 & $\begin{array}{l}0,032 \\
(0,006)^{*}\end{array}$ & $\begin{array}{c}0,032 \\
(0,006)^{*}\end{array}$ & $\begin{array}{c}0,034 \\
(0,006)^{*}\end{array}$ \\
\hline 1993 & $\begin{array}{c}0,020 \\
(0,006)^{*}\end{array}$ & $\begin{array}{c}0,020 \\
(0,006)^{*}\end{array}$ & $\begin{array}{c}0,021 \\
(0,006)^{*}\end{array}$ \\
\hline 1994 & $\begin{array}{l}0,015 \\
(0,007)^{* *}\end{array}$ & $\begin{array}{c}0,015 \\
(0,007)^{\star *}\end{array}$ & $\begin{array}{l}0,013 \\
(0,006)^{* *}\end{array}$ \\
\hline 1995 & $\begin{array}{c}0,022 \\
(0,007)^{\star}\end{array}$ & $\begin{array}{c}0,022 \\
(0,007)^{\star}\end{array}$ & $\begin{array}{c}0,022 \\
(0,007)^{*}\end{array}$ \\
\hline 1996 & $\begin{array}{c}0,023 \\
(0,007)^{\star}\end{array}$ & $\begin{array}{c}0,024 \\
(0,007)^{*}\end{array}$ & $\begin{array}{c}0,024 \\
(0,006)^{*}\end{array}$ \\
\hline 1997 & $\begin{array}{c}0,029 \\
(0,007)^{*}\end{array}$ & $\begin{array}{c}0,029 \\
(0,007)^{*}\end{array}$ & $\begin{array}{l}0,030 \\
(0,007)^{*}\end{array}$ \\
\hline 1998 & $\begin{array}{c}0,031 \\
(0,007)^{*}\end{array}$ & $\begin{array}{c}0,031 \\
(0,007)^{*}\end{array}$ & $\begin{array}{c}0,031 \\
(0,007)^{*}\end{array}$ \\
\hline Constante & $\begin{array}{c}1,012 \\
(0,019)^{*}\end{array}$ & $\begin{array}{c}0,993 \\
(0,010)^{*}\end{array}$ & $\begin{array}{c}0,925 \\
(0,016)^{*}\end{array}$ \\
\hline $\mathrm{N}^{0}$ de Obs. & 346 & 346 & 346 \\
\hline
\end{tabular}

Nota: ${ }^{* *} \mathrm{e}^{* * *}$ significam que as variáveis são estatisticamente significantes aos níveis de $1 \%, 5 \%$ e $10 \%$, respectivamente. 